\title{
Quality improvement program decreases mortality after cardiac surgery
}

\author{
Sotiris C. Stamou, MD, PhD, Sara L. Camp, NP, Robert M. Stiegel, MD, Mark K. Reames, MD, Eric Skipper, MD, \\ Larry T. Watts, MD, Marcy Nussbaum, MS, Francis Robicsek, MD, PhD, and Kevin W. Lobdell, MD
}

Supplemental material is available online.
From the Department of Thoracic and Cardiovascular Surgery, Carolinas Heart Institute, Carolinas Medical Center, Charlotte, NC.

Received for publication June 4, 2007; revisions received July 27, 2007; accepted for publication Aug 27, 2007.

Address for reprints: Kevin W. Lobdell, MD, Carolinas Heart Institute, 1000 Blythe Blvd, Charlotte, NC 28203 (E-mail: kevin.lobdell @carolinas.org).

J Thorac Cardiovasc Surg 2008;136:494-9 $0022-5223 / \$ 34.00$

Copyright (C) 2008 by The American Association for Thoracic Surgery

doi:10.1016/j.jtcvs.2007.08.081
Objective: This study investigated the effects of a quality improvement program and goal-oriented, multidisciplinary protocols on mortality after cardiac surgery.

Methods: Patients were divided into two groups: those undergoing surgery (coronary artery bypass grafting, isolated valve surgery, or coronary artery bypass grafting and valve surgery) after establishment of the multidisciplinary quality improvement program (January 2005-December 2006, $\mathrm{n}=922$ ) and those undergoing surgery before institution of the program (January 2002-December 2003, $n=1289$ ). Logistic regression and propensity score analysis were used to adjust for imbalances in patients' preoperative characteristics.

Results: Operative mortality was lower in the quality improvement group (2.6\% vs $5.0 \%, P<.01)$. Unadjusted odds ratio was 0.5 (95\% confidence interval $0.3-0.8, P<.01)$; propensity score-adjusted odds ratio was 0.6 (95\% confidence interval 0.4-0.99, $P=.04)$. In multivariable analysis, diabetes $(P<.01)$, chronic renal insufficiency $(P=.05)$, previous cardiovascular operation $(P=.04)$, congestive heart failure $(P<.01)$, unstable angina $(P<.01)$, age older than 75 years $(P<.01)$, prolonged pump time $(P<.01)$, and prolonged operation $(P=.05)$ emerged as independent predictors of higher mortality after cardiac surgery, whereas quality improvement program $(P<.01)$ and male sex $(P=.03)$ were associated with lower mortality. Mortality decline was less pronounced in patients with than without diabetes $(P=.04)$.

Conclusion: Application of goal-directed, multidisciplinary protocols and a quality improvement program were associated with lower mortality after cardiac surgery. This decline was less prominent in patients with diabetes, and focused quality improvement protocols may be required for this subset of patients.

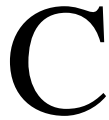
ardiothoracic surgery has a long history of commitment to improving the quality of patient care. Data collection and critical analysis have established high standards that may effectively decrease the rate of less acceptable outcomes. ${ }^{1,2}$ Recently, The Society of Thoracic Surgeons' executive committee created the quality measurement task force, a comprehensive quality measurement program for cardiothoracic surgery. ${ }^{2}$ Measurement of existing quality and identification of substantial deviations from best practice are the first steps in any continuous quality improvement program (QIP). Such an examination leads to focused interventions, after which improvements are documented with repeated measurements. ${ }^{3}$

In contrast to the integral role that publication plays in scientific discovery, publication in medical quality improvement has unfortunately had only a limited role to date. This lack of published reports has arguably deprived the health care system of rigorous scholarly evidence on improvement work and thus has slowed advancement of the improvement process. ${ }^{4,5}$ There is little evidence evaluating the effects on postoperative mortality after cardiac surgery of implementing QIPs and quality measurement. ${ }^{4,6-11}$ 


\section{Abbreviations and Acronyms \\ $\mathrm{AVR}=$ aortic valve replacement \\ $\mathrm{CABG}=$ coronary artery bypass grafting \\ QIP = quality improvement program}

This study was conducted in a large clinical setting to evaluate systematically the effects on mortality after cardiac surgery of the institution of a QIP and multidisciplinary protocols.

\section{Materials and Methods Patients}

The computerized database of the Division of Cardiothoracic Surgery at the Carolinas Heart Institute was used to select all patients who underwent coronary artery bypass grafting (CABG), isolated valve surgery, or valve surgery with $\mathrm{CABG}$, in our institution from January 2002 to December 2006. Patients were divided into two groups: those who had surgery $(\mathrm{CABG}$, isolated valve, or both CABG and valve surgery) after the establishment of the multidisciplinary QIP (January 2005-December 2006, n = 922) and those undergoing surgery before the institution of the QIP (non-QIP, January 2002-December 2003, $\mathrm{n}=1289$ ). Patients who underwent surgery during the transitional year of 2004 were not included in the analysis. The same group of cardiac surgeons, anesthesiologists, and perfusionists performed all operations for both periods. Baseline demographic characteristics, procedural data, and perioperative outcomes were recorded and entered prospectively in a prespecified database by a dedicated data-coordinating center.

\section{Medical Ethics Approval}

Study approval was sought and obtained from the investigational review board at our institution. Confidentiality of personal patient information was maintained at all times, consistent with the Health Insurance Portability and Accountability Act of 1996 regulations.

\section{Definitions}

Previous cerebrovascular accident was defined as history of central neurologic deficit persisting longer than 24 hours. Chronic renal insufficiency was defined as a serum creatinine value of at least $2.0 \mathrm{mg} / \mathrm{dL}$. Diabetes was defined as any history of diabetes mellitus, regardless of duration of disease or need for oral agents or insulin. Recent myocardial infarction was defined as myocardial infarction occurring within 7 days before the surgery. Depressed ejection fraction was defined as an ejection fraction less than $40 \%$. Prolonged ventilatory support was defined as pulmonary insufficiency requiring ventilatory support for longer than 24 hours. Postoperative stroke was defined as any new major (type II) neurologic deficit arising during hospitalization and persisting longer than 72 hours. ${ }^{12}$ Transient ischemic attacks were not included in this analysis. Strokes were confirmed by an independent neurologist, appropriate brain imaging, or both. Acute renal failure was defined as the increase of serum creatinine to both greater than $2.0 \mathrm{mg} / \mathrm{dL}$ and greater than twice the value of the most recent preoperative creatinine level. Prolonged hospital stay was defined as hospital stay longer than the 75 th percentile ( 9 days). Prolonged pump time and prolonged operative time were defined as pump and operative times longer than the 75 th percentile ( $>125 \mathrm{~min}$ and $>293 \mathrm{~min}$, respectively). Operative mortality included both (1) all deaths occurring during the hospitalization in which the operation was performed, even after 30 days, and (2) those deaths occurring after discharge from the hospital but within 30 days of the procedure, unless the cause of death was clearly unrelated to the operation. The Society of Thoracic Surgeons National Cardiac Database definitions were used for the purposes of the study.

\section{Quality Improvement Program}

The QIP was begun in 2004 to improve cardiac surgical outcomes. National trends toward increased acuity, aging patient populations, and declining volumes, as well as goals of transparency, pay for quality, and value-based competition, contributed to the impetus for change. The Society of Thoracic Surgeons National Cardiac Database and National Quality Forum metrics and guidelines ${ }^{3}$ focused our QIP. Evidenced-based intensive care unit management protocols and guidelines included communication tools (standardized handoff and goal sheets), sedation monitoring, respiratory protocols for early extubation and best pulmonary practices bundles, computerized euglycemia management, blood management, and an infection control program, (for detailed description of QIP protocols, see online Appendix E). Multidisciplinary intensive care unit rounds were a part of the QIP and included a nurse, charge nurse, nurse practitioner, respiratory therapist, pharmacist, and cardiac intensivist, as well as the cardiothoracic surgeons and residents.

\section{Data analysis}

Univariate comparisons of preoperative, operative, and postoperative variables were performed between QIP and non-QIP groups. Dichotomous variables were compared with a $\chi^{2}$ test of general association or a Fisher exact test for cell counts less than 5. All tests were 2 -sided. Some continuous variables had highly skewed distributions. They were therefore converted to dichotomous variables, and the upper 25th percentile was chosen as the cutoff point.

A multivariable, stepwise, backward logistic regression analysis was conducted to determine independent predictors of operative mortality. The criterion for a variable entry into the logistic model was a univariate probability level of $P<.05$. The quality of the fit of the logistic model was tested with the Hosmer-Lemeshow goodness-of-fit test. All statistical analyses were conducted with SAS software (SAS Institute, Inc, Cary, NC).

Propensity score adjustment was used on the postoperative outcomes to correct for differences between QIP and non-QIP groups at baseline. A logistic regression model was fitted where QIP or nonQIP was the outcome and baseline characteristics $(P<.1)$ from the bivariate analysis were the covariates. Propensity scores were generated and included as regression (covariance) adjustments in each of the logistic regression outcome models. ${ }^{13}$ The ability of the propensity score to balance effectively the compared groups at baseline was confirmed with separate logistic models that used QIP or nonQIP group type as the dependent variable and the covariate and propensity score as the independent variables (online Appendix E).

\section{Results}

\section{Preoperative Characteristics}

Univariate comparisons between QIP $(\mathrm{n}=922)$ and non-QIP groups $(n=1289)$ are presented in Table 1. QIP patients were more likely to be male and to have hypertension, 
chronic obstructive pulmonary disease (mild), and threevessel coronary artery disease than were non-QIP patients. Non-QIP patients were more likely to be older; to be in New York Heart Association functional class III or IV; and to have lower ejection fraction, recent acute myocardial infarction, or unstable angina than were QIP patients; they were also less likely to be operated on electively.

\section{Operative and Postoperative Characteristics}

Operative and postoperative patient characteristics are presented in Table 2. QIP patients were more likely to undergo valve surgery or both $C A B G$ and valve surgery than were non-QIP patients. Pump, operative, and crossclamp times were more prolonged for QIP patients than for non-QIP patients. QIP patients had lower rates of operative mortality, postoperative sepsis, acute renal failure, and cardiac tamponade than were non-QIP patients, and they were more likely to be extubated within 6 hours after surgery. The reintubation

\section{TABLE 1. Baseline patient demographic characteristics}

\begin{tabular}{|c|c|c|c|}
\hline & $\begin{array}{c}\text { OIP } \\
(\mathrm{N}=922)\end{array}$ & $\begin{array}{c}\text { Non-0IP } \\
\text { (N = 1289) }\end{array}$ & $\begin{array}{c}P \\
\text { value }\end{array}$ \\
\hline Male & $684(74 \%)$ & $907(70 \%)$ & .05 \\
\hline Hypertension & $724(79 \%)$ & $948(74 \%)$ & .01 \\
\hline Diabetes & $342(37 \%)$ & $491(38 \%)$ & .63 \\
\hline Chronic renal insufficiency & $50(5 \%)$ & $61(5 \%)$ & .46 \\
\hline Previous cerebrovascular accident & $95(10 \%)$ & $136(11 \%)$ & .85 \\
\hline \multicolumn{3}{|l|}{ Chronic obstructive pulmonary disease } & .01 \\
\hline Mild & $70(8 \%)$ & $94(7 \%)$ & \\
\hline Moderate & $21(2 \%)$ & $83(6 \%)$ & \\
\hline Severe & $34(4 \%)$ & $28(2 \%)$ & \\
\hline None & $797(86 \%)$ & $1084(84 \%)$ & \\
\hline Previous cardiovascular operation & $319(35 \%)$ & $482(37 \%)$ & .18 \\
\hline Congestive heart failure & $153(17 \%)$ & $240(19 \%)$ & .22 \\
\hline Unstable angina & $130(14 \%)$ & $324(25 \%)$ & .01 \\
\hline Recent myocardial infarction & $154(17 \%)$ & $313(24 \%)$ & .01 \\
\hline Age $>75$ y & $112(12 \%)$ & $190(15 \%)$ & .08 \\
\hline Ejection fraction $<40 \%$ & $202(22 \%)$ & $349(27 \%)$ & .01 \\
\hline \multicolumn{3}{|c|}{ New York Heart Association functional class } & .01 \\
\hline I & $45(5 \%)$ & $30(2 \%)$ & \\
\hline II & $390(42 \%)$ & $227(18 \%)$ & \\
\hline III & $347(38 \%)$ & $637(49 \%)$ & \\
\hline IV & $140(15 \%)$ & $395(31 \%)$ & \\
\hline \multicolumn{3}{|l|}{ No. of diseased vessels } & .01 \\
\hline 0 & $182(20 \%)$ & $133(10 \%)$ & \\
\hline 1 & $76(8 \%)$ & $61(5 \%)$ & \\
\hline 2 & $409(44 \%)$ & $887(70 \%)$ & \\
\hline 3 & $254(28 \%)$ & $195(15 \%)$ & \\
\hline \multicolumn{3}{|l|}{ Case priority } & .01 \\
\hline Elective & $315(34 \%)$ & $363(28 \%)$ & \\
\hline Urgent & $535(58 \%)$ & $789(61 \%)$ & \\
\hline Emergency & $72(8 \%)$ & $137(11 \%)$ & \\
\hline
\end{tabular}

All data represent numbers and percentages of patients. QIP, Quality improvement program.
TABLE 2. Intraoperative and postoperative patient characteristics

\begin{tabular}{ccc} 
OIP & Non-0IP & $P$ \\
$(\mathrm{~N}=922)$ & $(\mathrm{N}=1289)$ & value \\
\hline
\end{tabular}

\begin{tabular}{|c|c|c|c|}
\hline \multicolumn{4}{|l|}{ Operative characteristics } \\
\hline Type of surgery & & & .01 \\
\hline CABG & $646(70 \%)$ & $1060(82 \%)$ & \\
\hline Valve & $195(21 \%)$ & $145(11 \%)$ & \\
\hline CABG plus valve & $81(9 \%)$ & $84(7 \%)$ & \\
\hline Prolonged pump time ( $>125 \mathrm{~min})$ & $252(27 \%)$ & $286(22 \%)$ & .01 \\
\hline $\begin{array}{l}\text { Prolonged crossclamp time } \\
\text { (>78 } \mathrm{min})\end{array}$ & $258(28 \%)$ & $286(22 \%)$ & .01 \\
\hline $\begin{array}{l}\text { Prolonged operative time } \\
\text { (>293 } \mathrm{min})\end{array}$ & $244(26 \%)$ & $302(23 \%)$ & .12 \\
\hline \multicolumn{4}{|l|}{ Postoperative outcomes } \\
\hline Stroke & $25(3 \%)$ & $21(2 \%)$ & .08 \\
\hline Sepsis & $21(2 \%)$ & $50(4 \%)$ & .04 \\
\hline Renal failure & $51(6 \%)$ & $105(8 \%)$ & .02 \\
\hline Atrial fibrillation & $303(33 \%)$ & $349(27 \%)$ & .01 \\
\hline Hemodialysis & $15(2 \%)$ & $27(2 \%)$ & .43 \\
\hline Cardiac arrest & $20(2 \%)$ & $44(3 \%)$ & .09 \\
\hline Intra-aortic balloon pump & $2(0.2 \%)$ & $2(0.2 \%)$ & $>.999$ \\
\hline $\begin{array}{l}\text { Hemorrhage-related } \\
\text { reexploration }\end{array}$ & $51(6 \%)$ & $85(7 \%)$ & .31 \\
\hline Blood transfusion & $365(40 \%)$ & $526(41 \%)$ & .57 \\
\hline Cardiac tamponade & $2(0.2 \%)$ & $20(1.6 \%)$ & .01 \\
\hline Mediastinitis & $10(1.1 \%)$ & $8(0.6 \%)$ & .23 \\
\hline In-hospital mortality & $20(2 \%)$ & $61(5 \%)$ & .01 \\
\hline Operative mortality & $24(3 \%)$ & $65(5 \%)$ & .01 \\
\hline \multicolumn{4}{|l|}{ Cause of death } \\
\hline Cardiac & $10(42 \%)$ & $45(69 \%)$ & .01 \\
\hline Infection & $0(0 \%)$ & $2(3 \%)$ & \\
\hline Stroke & $4(17 \%)$ & $7(11 \%)$ & \\
\hline Respiratory failure & $5(21 \%)$ & $7(11 \%)$ & \\
\hline Acute renal failure & $1(5 \%)$ & $3(5 \%)$ & \\
\hline Other & $3(13 \%)$ & $1(2 \%)$ & \\
\hline Unknown & $1(5 \%)$ & $0(0 \%)$ & \\
\hline Return to ICU & $73(8 \%)$ & $108(8 \%)$ & .70 \\
\hline ICU stay $<24 \mathrm{~h}$ & $295(32 \%)$ & $568(44 \%)$ & .01 \\
\hline Prolonged stay $(>9 d)$ & $210(23 \%)$ & $269(21 \%)$ & .28 \\
\hline Reintubation & $65(7 \%)$ & $64(5 \%)$ & .04 \\
\hline Ventilation $<6 \mathrm{~h}$ & $490(53 \%)$ & $490(38 \%)$ & .01 \\
\hline Prolonged intubation ( $>24 \mathrm{~h}$ ) & $88(10 \%)$ & $151(12 \%)$ & .11 \\
\hline
\end{tabular}

All data represent numbers and percentages of patients. QIP, Quality improvement program; $C A B G$, coronary artery bypass grafting; ICU, intensive care unit.

rate, however, was higher in the QIP group than in the non-QIP group. No significant differences were found in prolonged ventilation, prolonged stay, mediastinitis, or hemorrhage-related reexploration.

\section{Operative Mortality}

Univariate analysis. In univariate analysis, operative mortality was lower in the QIP group than in the non-QIP 
TABLE 3. Multivariate logistic regression analysis model of operative mortality

\begin{tabular}{|c|c|c|c|c|c|}
\hline & $\exists$ Coefficient & SE & $\begin{array}{l}\text { Odds } \\
\text { ratio }\end{array}$ & $\begin{array}{c}95 \% \\
\text { Confidence } \\
\text { interval }\end{array}$ & $\begin{array}{c}P \\
\text { value }\end{array}$ \\
\hline OIP & -0.29 & 0.14 & 0.6 & $0.3-1.0$ & .04 \\
\hline Male sex & -0.26 & 0.14 & 0.6 & $0.4-0.9$ & .03 \\
\hline Diabetes & 0.34 & 0.13 & 1.2 & $1.2-3.2$ & .01 \\
\hline $\begin{array}{l}\text { Chronic renal } \\
\text { insufficiency }\end{array}$ & 0.37 & 0.19 & 2.7 & $1.0-4.2$ & .05 \\
\hline Reoperation & 0.24 & 0.12 & 1.6 & $1.0-2.5$ & .04 \\
\hline Congestive heart failure & 0.51 & 0.12 & 2.8 & $1.8-4.5$ & .01 \\
\hline Unstable angina & 0.40 & 0.14 & 2.2 & $1.3-3.8$ & .01 \\
\hline Age $>75 y$ & 0.41 & 0.13 & 2.3 & $1.3-3.6$ & .01 \\
\hline Prolonged pump time & 0.46 & 0.14 & 2.5 & $1.4-4.2$ & .01 \\
\hline Prolonged operative time & 0.27 & 0.14 & 1.7 & $1.0-3.0$ & .05 \\
\hline OIP and no diabetes & -0.26 & 0.13 & 0.6 & $0.4-0.9$ & .04 \\
\hline
\end{tabular}

QIP, Quality improvement program.

group ( $2.6 \%$ vs $5.0 \%, P<.01)$. Causes of death for the two groups are presented in Table 2. It is apparent that the decrease in operative mortality for QIP was almost entirely attributable to a marked decrease in cardiac-related death.

Multivariate analysis. The results of the multivariable logistic regression analysis are summarized in Table 3. The $\mathrm{C}$ statistic for the model is 0.8 , which indicates a good fit. Diabetes $(P<.01)$, chronic renal insufficiency $(P=.05)$, previous cardiovascular operation $(P=.04)$, congestive heart failure $(P<.01)$, unstable angina $(P<.01)$, age older than 75 years $(P<.01)$, prolonged pump time $(P<.01)$, and prolonged operative time $(P=.05)$ emerged as independent predictors of higher mortality after cardiac surgery.

QIP $(P=.04)$, male sex $(P=.03)$, and interaction of QIP and nondiabetic status $(P=.04)$ were associated with lower mortality (Figure 1). There was a lower relative decline in mortality among patients with diabetes than among those without diabetes. For patients with diabetes, QIP and nonQIP mortalities were 5\% and 6\%, respectively, whereas for patients without diabetes, the respective values for QIP and non-QIP groups were $2 \%$ and $5 \%$.

Propensity score analysis. The propensity scoreadjusted odds ratio demonstrated a significant decrease in mortality for the QIP group (odds ratio $0.6,95 \%$ confidence interval $0.4-0.99, P=.04$ ). Figure 2 shows the general decline of operative mortality with time.

\section{Discussion}

Cardiac surgery remains at the forefront of risk model development and clinical quality monitoring. Recently, the Society of Thoracic Surgeons created the Quality Measurement Task Force to develop comprehensive summary quality measures encompassing multiple domains of quality. ${ }^{14}$ Implementa-

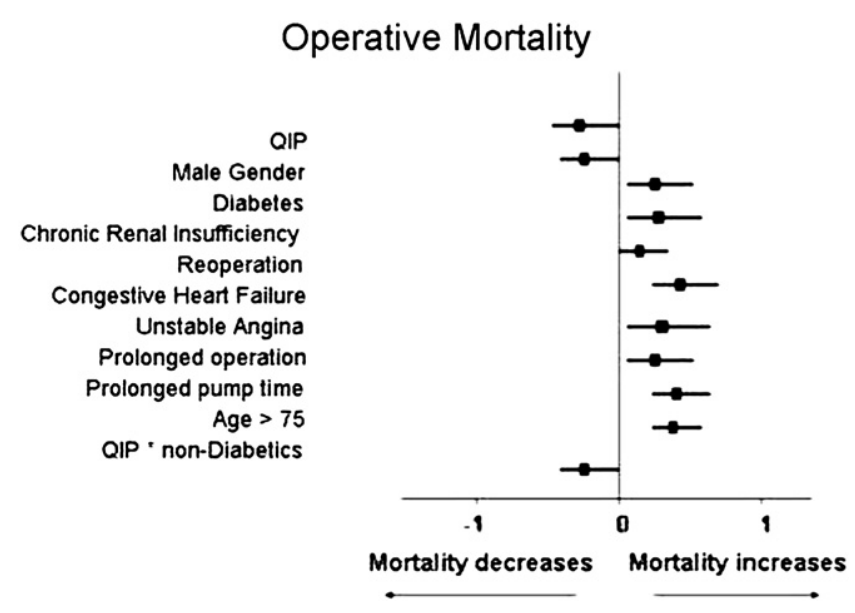

Figure 1. Independent predictors of operative mortality after cardiac surgery (multivariable logistic regression analysis). QIP, Quality improvement program.

tion of the guidelines included in the report of the Quality Measurement Task Force is expected to foster improvement of outcomes. This study sought to investigate in a riskadjusted fashion whether a systematic and consistent implementation of a QIP would decrease mortality after cardiac surgery.

\section{Principal Findings}

We demonstrated that a QIP and multidisciplinary protocols are powerful tools associated with decreased mortality after cardiac surgery. In our institution, mortality dropped almost $50 \%$ (from 5.0\% to 2.6\%); this decrease in operative mortality for the QIP group was almost entirely attributable to a marked decrease in cardiac-related deaths (Table 2). Specifically, there was a decrease in the incidence of cardiac causes of death by 30\% in the QIP group relative to the non-QIP group.

This decline in operative mortality was made feasible by the consistent application of multiple protocols, including standardized communication tools and goal sheets, sedation monitoring, respiratory protocols for early extubation and best pulmonary practices bundles, computerized euglycemia management, multidisciplinary intensive care unit rounds, blood management, and an infection control program.

\section{Predictors of Operative Mortality}

In the multivariable analysis, well-documented risk factors such as diabetes, ${ }^{15}$ female sex, ${ }^{16}$ renal insufficiency, ${ }^{17}$ reoperation, ${ }^{18}$ congestive heart failure, unstable angina, ${ }^{19}$ advanced age, ${ }^{20}$ prolonged pump time, and increased operative time $^{21}$ increased the risk of mortality in this study, as they have done in other studies. The interaction of QIP and nondiabetic status indicates that there were different modes of 


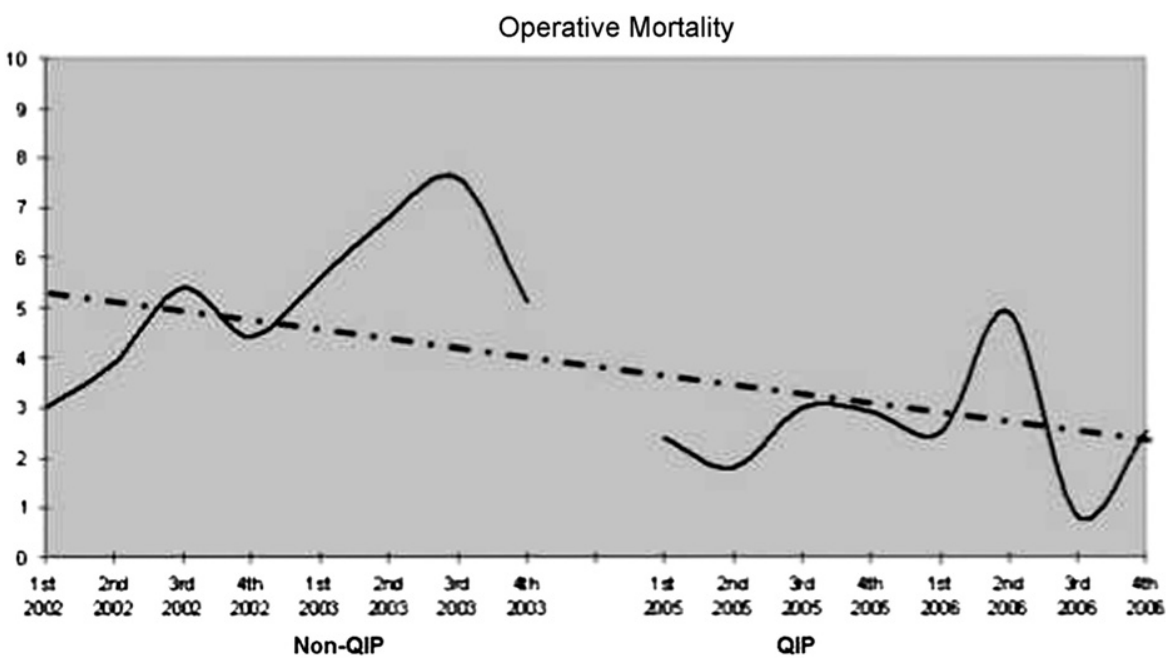

Figure 2. Graph demonstrating steady decline in operative mortality with time after institution of quality improvement program (QIP). Gray line represents line of best fit.

mortality decline for patients with and without diabetes. More specifically, the mortality rate for patients with diabetes was less affected by the process improvement initiatives, as has been previously shown. ${ }^{22}$

\section{Clinical Implications}

For common surgical procedures, processes of care vary widely among cardiac surgical programs. Important components of a QIP program include a systems-based approach, standardization, team building, consistent and accurate communication, and active management of change and quality. Use of composite indicators is useful to drive performance improvement after cardiac surgery. This study, which demonstrated a $48 \%$ decline in operative mortality after implementation of a QIP, is among the first to demonstrate such a finding by the use of a rigorous risk-adjusted methodology and a large sample size. The mortality decline with the QIP was less pronounced for patients with diabetes, and future improvement processes should focus on this particular subset of patients.

\section{Study Limitations}

Limitations of this study include all those inherent in any retrospective, single-institution analysis. This was a nonrandomized study in which unmeasured patient or procedure-related variables may have influenced the study results. Furthermore, this investigation was conducted at a large tertiary referral center, and the results may not be broadly representative of community practice. Among the strengths of this study are the large cohort of patients, the prospective entry of all data elements into a cardiac surgical research database with strict definitions, and analysis of data performed with appropriately risk-adjusted statistical models to adjust for differences in preoperative risk factors.

\section{Conclusions}

The systematic and consistent implementation of a QIP in conjunction with the application of multidisciplinary protocols and quality improvement strategies decreased mortality after cardiac surgery. This decrease in postoperative mortality was less pronounced in patients with diabetes, and future quality improvement programs should focus on this high-risk category.

\section{References}

1. Shahian DM, Grover FL, Anderson RP, Edwards F. Quality measurement in adult cardiac surgery: introduction. Ann Thorac Surg. 2007; 83(4 Suppl):S1-2.

2. Shahian DM, Edwards FH, Ferraris VA, Haan CK, Rich JB, Normand SL, et al. Quality measurement in adult cardiac surgery: part 1 -Conceptual framework and measure selection. Ann Thorac Surg. 2007;83(4 Suppl):S3-12.

3. Eagle KA, Guyton RA, Davidoff R, Edwards FH, Ewy GA, Gardner TJ, et al. ACC/AHA 2004 guideline update for coronary artery bypass graft surgery: a report of the American College of Cardiology/American Heart Association Task Force on Practice Guidelines (Committee to Update the 1999 Guidelines for Coronary Artery Bypass Graft Surgery) [published erratum appears in Circulation. 2005;111:2014]. Circulation. 2004; 110:e340-437.

4. Davidoff F, Batalden P. Toward stronger evidence on quality improvement. Draft publication guidelines: the beginning of a consensus project. Qual Saf Health Care. 2005;14:319-25.

5. Surgenor SD, O'Connor GT, Lahey SJ, Quinn R, Charlesworth DC, Dacey LJ. Predicting the risk of death from heart failure after coronary artery bypass graft surgery. Anesth Analg. 2001;92:596-601.

6. O'Connor GT, Plume SK, Olmstead EM, Coffin LH, Morton JR, Maloney CT, et al. A regional prospective study of in-hospital mortality associated with coronary artery bypass grafting. The Northern New England Cardiovascular Disease Study Group. JAMA. 1991;266:803-9.

7. Kasper JF, Plume SK, O'Connor GT. A methodology for QI in the coronary artery bypass grafting procedure involving comparative process analysis. QRB Qual Rev Bull. 1992;18:129-33.

8. Moscucci M, Rogers EK, Montoye C, Smith DE, Share D, Donnell MO, et al. Association of a continuous quality improvement initiative with practice and outcome variations of contemporary percutaneous coronary interventions. Circulation. 2006;113:814-22.

9. Ferguson TB Jr, Peterson ED, Coombs LP, Eiken MC, Carey ML, Grover FL, et al. Use of continuous quality improvement to increase 
use of process measures in patients undergoing coronary artery bypass graft surgery: a randomized controlled trial. JAMA. 2003;290:49-56.

10. Griffith D, Hampton D, Switzer M, Daniels J. Facilitating the recovery of open heart surgery patients through quality improvement efforts and CareMAP implementation. Am J Crit Care. 1996;5:346-52.

11. Grover FL, Cleveland JC, Shroyer LW. Quality improvement in cardiac care. Arch Surg. 2002;137:28-36.

12. Roach GW, Kanchuger M, Mangano CM, Newman M, Nussmeier N, Wolman R, et al. Adverse cerebral outcomes after coronary bypass surgery. Multicenter Study of Perioperative Ischemia Research Group and the Ischemia Research and Education Foundation Investigators. N Engl J Med. 1996;335:1857-63.

13. D'Agostino RB Jr. Propensity score methods for bias reduction in the comparison of a treatment to a non-randomized control group. Stat Med. 1998; 17:2265-81.

14. O'Brien SM, Shahian DM, DeLong ER, Normand SL, Edwards FH, Ferraris VA, et al. Quality measurement in adult cardiac surgery: part 2 -statistical considerations in composite measure scoring and provider rating. Ann Thorac Surg. 2007;83(4 Suppl):S13-26.

15. Schmeltz LR, DeSantis AJ, Thiyagarajan V, Schmidt K, O'SheaMahler E, Johnson D, et al. Reduction of surgical mortality and morbidity in diabetic patients undergoing cardiac surgery with a combined intravenous and subcutaneous insulin glucose management strategy. Diabetes Care. 2007;30:823-8.
16. Fisher LD, Kennedy JW, Davis KB, Maynard C, Fritz JK, Kaiser G, et al. Association of sex, physical size, and operative mortality after coronary artery bypass in the Coronary Artery Surgery Study (CASS). J Thorac Cardiovasc Surg. 1982;84:334-41.

17. Devbhandari MP, Duncan AJ, Grayson AD, Fabri BM, Keenan DJ, Bridgewater B, et al. Effect of risk-adjusted, non-dialysis-dependent renal dysfunction on mortality and morbidity following coronary artery bypass surgery: a multi-centre study. Eur J Cardiothorac Surg. 2006;29: 964-70.

18. Stamou SC, Pfister AJ, Dangas G, Dullum MK, Boyce SW, Bafi AS, et al. Beating heart versus conventional single-vessel reoperative coronary artery bypass. Ann Thorac Surg. 2000;69:1383-7.

19. Corbineau H, Lebreton H, Langanay T, Logeais Y, Leguerrier A. Prospective evaluation of coronary arteries: influence on operative risk in coronary artery surgery. Eur J Cardiothorac Surg. 1999;16:429-34.

20. Stamou SC, Dangas G, Dullum MK, Pfister AJ, Boyce SW, Bafi AS, et al. Beating heart surgery in octogenarians: perioperative outcome and comparison with younger age groups. Ann Thorac Surg. 2000;69: $1140-5$.

21. Rady MY, Ryan T, Starr N. Perioperative determinants of morbidity and mortality in elderly patients undergoing cardiac surgery. Crit Care Med. 2001;29:S163-72.

22. Van den Berghe G, Wilmer A, Milants I, Wouters PJ, Bouckaert B, Bruyninckx F, et al. Intensive insulin therapy in mixed medical/surgical intensive care units: benefit versus harm. Diabetes. 2006;55:3151-9. 
APPENDIX

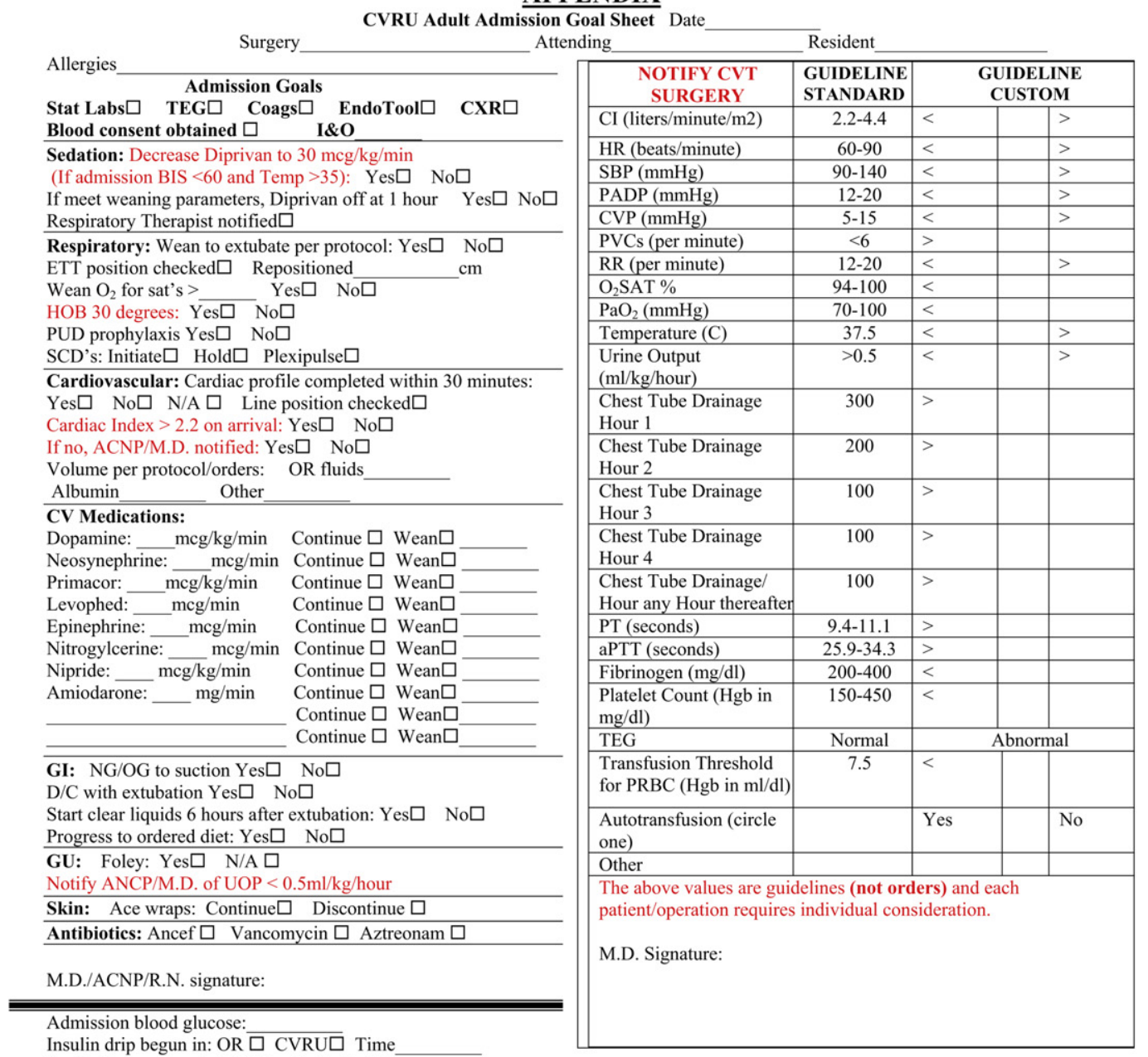

Insulin drip begun in: OR $\square$ CVRU Time

Insulin bolus given in OR: Yes $\square$ No $\square$ Time

Date:

Admission Extubation Goals

Admission Time: $\quad$ Expected Time of Extubation:

Admission BIS: $\longrightarrow$ BIS at expected Time of Extubation:

Diprivan off at:

Last narcotic/sedative in CVRU

Reason $\overline{\text { Reversal given: Yes } \square \text { Time: }}$

Anesthesiologist/CRNA:

Significant Information:

M.D. Order to keep intubated? $\square$ M.D. name: Reason:

Preop Creatine_ Renal failure preop

\begin{tabular}{|c|c|c|c|c|c|c|c|}
\hline & Admission & $1^{\text {st }}$ Hour & $2^{\text {nd }}$ Hour & $3^{\text {rd }}$ Hour & $4^{\text {th }}$ Hour & $5^{\text {th }}$ Hour & $6^{\text {th }}$ Hour \\
\hline Chest tube output & & & & & & & \\
\hline \multicolumn{8}{|l|}{ Urine Output } \\
\hline \multicolumn{8}{|l|}{ Cardiac Index } \\
\hline \multirow{2}{*}{\multicolumn{8}{|c|}{ Temperature }} \\
\hline & & & & & & & \\
\hline Diprivan $\mathrm{mcg} / \mathrm{kg} / \mathrm{min}$ & & & *OFF & & & & \\
\hline BIS & & & & & & & \\
\hline
\end{tabular}

Respiratory Parameters at Time of Extubation: Pass $\square$ Fail $\square$ Reason

ABG:

$1^{\text {st }}$ attempt: Time _ NIF

$2^{\text {nd }}$ attempt: Time $-\mathrm{NIF}$

FVC

FVC

TV $\quad \mathrm{Ve}$

RR

$\mathrm{ETCO}_{2}$

Admission R.N.:

Admission Respiratory Therapist:

Expected Time of Extubation R.N.: 
Expected Time of Extubation Respiratory Therapist:

CVRU Adult Report/Goal Sheet Date_ POD \#

Patient Sticker

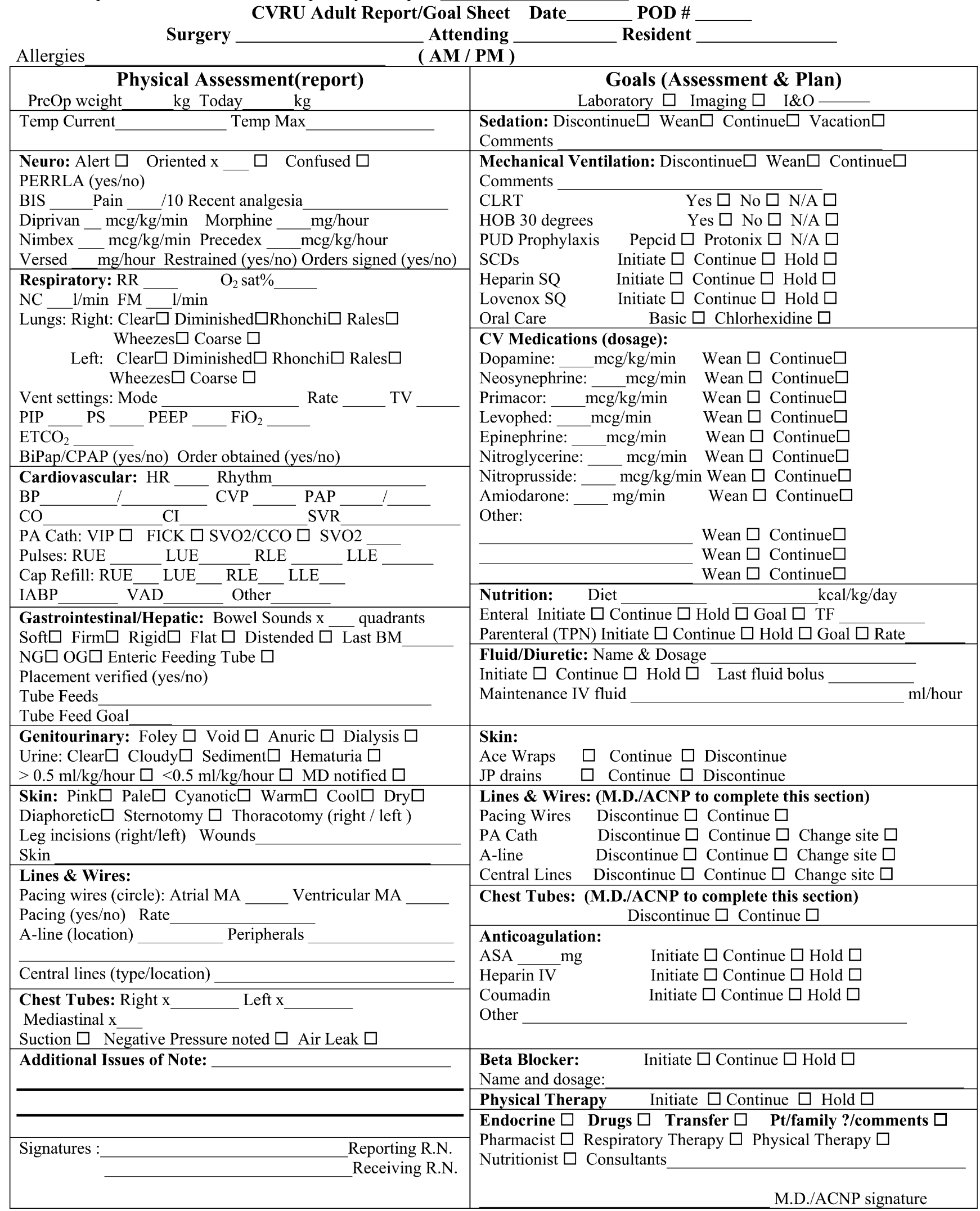


Carolinas Medical Center

Patient Sticker

Department of Anesthesia CHI/CVRU Transfer Record

*PLEASE SEND 30 MIN BEFORE ARRIVAL TO CVRU*

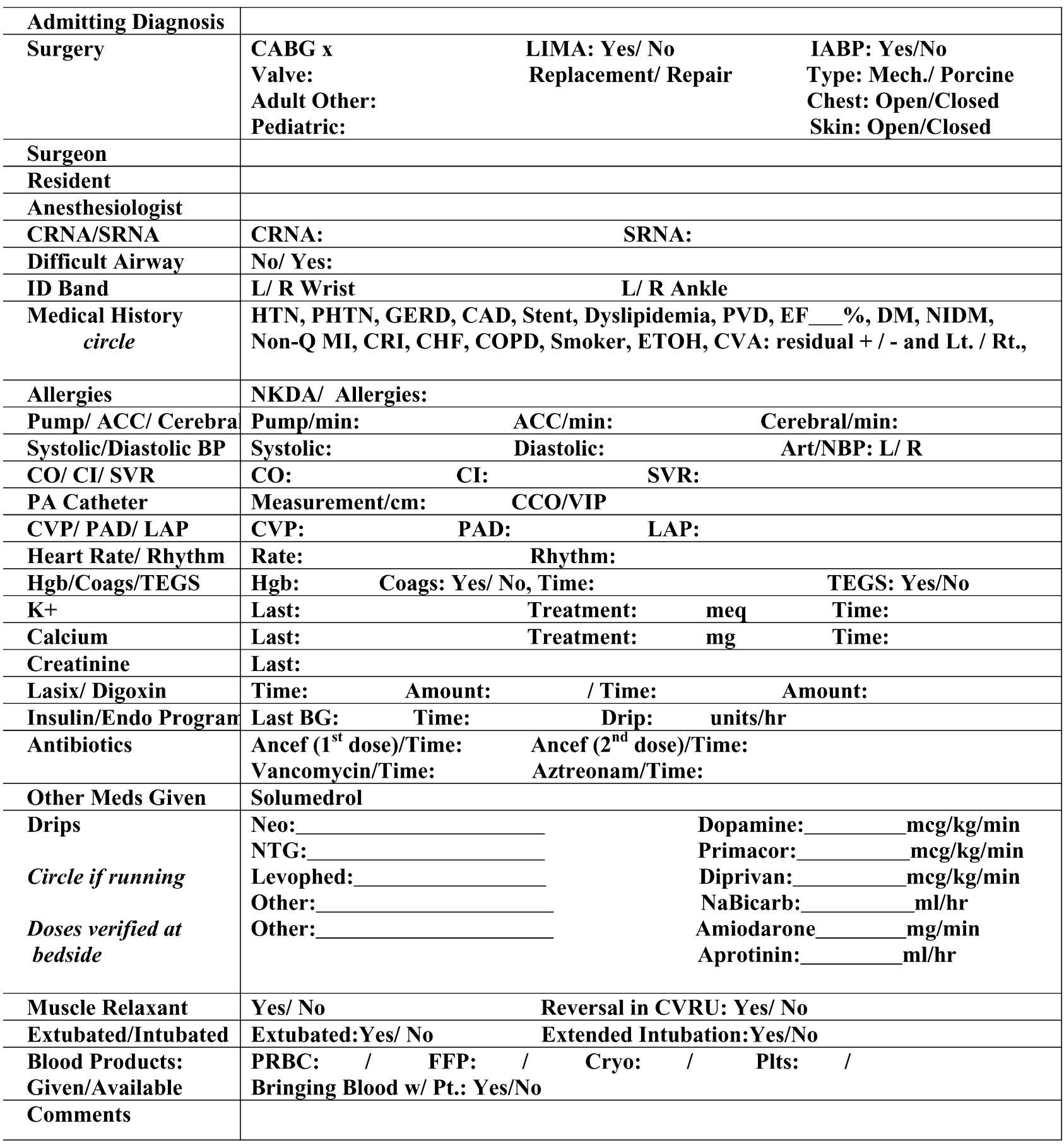

NOTE: See anesthesia record for fluid totals (IV fluids, EBL, Urine output) / Blanks completed on arrival Signatures of Report Given/ Received: CRNA CVRU RN Transfer of Care at: 


\section{Carolinas Medical Center (CMC) Post Cardio-Pulmonary Bypass Adult Orders}

CMC - CVRU

Initiate: CMC Post Cardio-Pulmonary Bypass Adult Orders

Verify Allergies

Admit to CVRU

Status Post:

List surgeon as Attending

Initiate: $\mathrm{CABG}$ pathway (for all $\mathrm{CABG}$ and valve patients)

Labs

On Arrival to CVRU:

ABG, Hgb, Potassium, Ionized Calcium, Magnesium, Coags and Glucose

If a TEG has not been performed in the OR obtain one upon admission.

ABGs PRN

Basic Metabolic Panel PRN

Ionized calcium PRN

Magnesium PRN

Glucose PRN

Potassium PRN

CBC PRN

Coags PRN

Hemoglobin PRN

Diagnostics:

PA portable CXR within 30 minutes of arrival to CVRU (CVRU to call request)

CXR when chest tubes removed

* May obtain CXR if patient in respiratory distress

* Daily CXR if patient remains intubated

* EKG PRN

Dressings:

* Remove ACE bandage on POD \#1 (or if detrimental to leg)

* Redress all incision sites and chest tube sites for drainage PRN (remove ACE if saturated and redress)

* Change sternal dressing daily and PRN, paint lightly with povidone/iodine (Betadine) on each side of incision

and re-dress with gauze and secure with silk tape.

Equipment:

* Foley Catheter to straight drainage

* Chest tubes $20 \mathrm{~cm}$ suction

* NG/OG tube to $30-50 \mathrm{~cm}$ intermittent wall suction

VS and Hemodynamic Parameters

BP Q15 minutes while on vasodilators (excluding nitroglycerin), inotropes or vasoconstrictors

BP Q1H when off all vasoactive drips and condition stable

BP Q4H when invasive lines are discontinued

Q1H: RR, $\mathrm{SVO}_{2}, \mathrm{CCO}$, Pulse Oximetry, PAP, CVP, LAP, RV

Q1H: IABP systolic, augmented, diastolic, and mean pressures

Q1H: IABP distal pedal pulse and left arm pulses

Q1H: RVAD, LVAD or BiVAD settings

Page 2 of 4

1-5180-0003 CMC Post Cardio-pulmonary Bypass Adult Orders

1-5180-0003-a-8-06

Q1H: Pulses in limbs with invasive lines

Q1H: Input and Output

Q2H: Temp, pulses, and capillary refill

Wean hemoactive drips if cardiac index greater than or equal to 2

Document hemodynamic profile Q4H and PRN while on vasoconstrictors, Inotropic drugs

Respiratory

Initiate: CMC Cardiovascular Respiratory Post Op Orders

Emergency Treatment Parameters

Pulseless V tach or V fib

Initiate Pulseless Arrest Algorithm*

Asystole and PEA

Initiate Pulseless Arrest Algorithm*

Symptomatic Bradycardia (Per ACLS Protocol)

Initiate Bradycardia Algorithm*

*ACLS Protocol per American Heart Association (AHA) guidelines

STAT EKG for onset of chest pain and/or sudden tachydysrhythmia

Treatment of Hypertension (for first 24 hours post-op): Systolic greater than 160

Nitroprusside (Nipride) $50 \mathrm{mg} / 250 \mathrm{ml}$ D5W to maintain systolic BP as designated by MD

May initiate the following to reduce or eliminate Nipride use after systolic BP controlled 
Labetalol 5-10 mg IV Q15 minutes (not to exceed $60 \mathrm{mg}$ total), if HR 80 or greater, normal SVR and no COPD or

asthma

Enalapril (Vasotec) $1.25 \mathrm{mg}$ IV Q15minute (not to exceed $2.5 \mathrm{mg}$ total), if HR less than 80 , and

elevated SVR

Treatment of sustained/persistent Hypotension

Adjust/discontinue vasodilator, as able to maintain systolic BP at patient's preoperative baseline

For low filling pressures with associated hypotension (PCWP less than 18 and PAD less than 20) AND

$\mathrm{Hgb}$

greater than 7 , give up to 4 bottles $(1000 \mathrm{ml}) 5 \%$ Albumin

If filling pressures are adequate with low systolic BP, begin Dopamine $400 \mathrm{mg} / 250 \mathrm{ml} \mathrm{D} 5 \mathrm{~W}$ and titrate up to

$10 \mathrm{mcg} / \mathrm{kg} /$ minutes to maintain systolic BP

Treatment for Low Cardiac Index(CI)

Give 5\% albumin (up to $500 \mathrm{ml}$ ) PRN for CI less than 2 and PCWP less than 18 or PAD less than 20

Pacemaker orders:

* Check Pacemaker Q Shift to override rhythm and threshold

* Keep Pacemaker on demand at rate of 50 unless pacer misfiring

* If pacer is misfiring, keep Pacemaker connected and in off position, until patient transfer

If HR drops below patient baseline or patient develops JR: Pacemaker may be utilized for support.

On transfer, if POD \#2 and in SR, remove Pacemaker, ground and insulate wires, label and tape wires

to chest

\section{General Care:}

Weight patient daily prior to 0600

May complete OR fluids

Keep HOB elevated at least 20-30 degrees while patient on ventilator

Chlorhexidine (Hibiclens) bath daily x 3 post op

* Continue Nitroglycerin (NTG) overnight if patient has had recent MI or Emergency surgery, IMA or radial artery

harvest

Insert NG/OG tube if patient's abdomen distended or with persistent vomiting

Page 3 of 4

1-5180-0003 CMC Post Cardio-pulmonary Bypass Adult Orders

1-5180-0003-a-8-06

Autotransfusion:

* Call for order to initiate if output greater than $200 \mathrm{ml}$ in first 4 hours

Discontinue Autotransfusion after 12 hours (contact physician for orders if patient bleeding persists)

Pharmacy

Discontinue all pre operative medications.

Sodium Bicarbonate as started in OR: $150 \mathrm{mEq} / 1000 \mathrm{ml}$ D5W IV at $\mathrm{ml} /$ hour $(1 \mathrm{ml} / \mathrm{kg} / \mathrm{hr}) \mathrm{x}$ $\overline{4 \text { hours, }}$

then $\quad \mathrm{ml} /$ hour $(0.3 \mathrm{ml} / \mathrm{kg} /$ hour $) \times 20$ hours

D5 $1 / 4 \mathrm{NS}$ with $30 \mathrm{mEq} \mathrm{KCl} / / \mathrm{L} \mathrm{IV}$ at $50 \mathrm{ml} /$ hour. If patient is receiving a sodium bicarbonate infusion, adjust this

fluid so that the total rate is $50 \mathrm{ml} /$ hour. Convert to PRN adaptor when po intake is adequate.

Discontinue $\mathrm{KCl}$ from above fluid if potassium is greater than $4.7 \mathrm{and} /$ or urine output is less than 0.5

$\mathrm{ml} / \mathrm{kg} /$ hour

Concentrate IV drips as needed to reduce fluid intake

Flush PRN adapter Q12H and PRN after use with NS

Famotidine (Pepcid) $20 \mathrm{mg}$ IV Q12H, change to po $\mathrm{x} 48$ hours when patient is extubated. Notify

Pharmacy.

Cefazolin (Ancef) $1 \mathrm{gm}$ IV Q8H x 3 doses post op Next dose due

If patient received vancomycin in the OR, give vancomycin $1 \mathrm{gm}$ IV 12 hours from last dose in the OR. If serum creatinine is above $2 \mathrm{mg} / \mathrm{dl}$, do not give another dose of vancomycin. Next dose due

If patient received Aztreonam in the OR, give $1 \mathrm{gm}$ Q8H x 3 doses. Next dose due

Enteric Coated Aspirin $325 \mathrm{mg}$ po daily when patient able to take po's (CABG patients only) Mupirocin (Bactroban) ointment to both nares BID x 9 doses. Apply with swab. Pharmacy to send one tube.

Sodium Bicarbonate $50 \mathrm{mEq}$ IV for every base excess of negative 6 on ABG result

(ex. for BE negative 12 , give $100 \mathrm{mEq}$ )

Heparin 1000 units $/ 500 \mathrm{ml} \mathrm{NS}$ to maintain pressure lines

Morphine 2 -10 mg IV Q1H for tube tolerance and/or severe pain while on ventilator

Morphine 2-4 mg IV Q1H PRN for severe pain when extubated

Midazolam (Versed) 2-10mg IV Q1 H PRN for extreme agitation/ tube tolerance while on ventilator.

Ondansetron (Zofran) $4 \mathrm{mg}$ IV Q6H PRN Nausea/Vomiting

Promethazine (Phenergan) 12.5mg IV Q4H PRN N/V if Zofran is not effective.

Zolpidem (Ambien) $5 \mathrm{mg}$ QHS PRN sleep. May repeat $\mathrm{x} 1$ dose in one hour

Lorazepam (Ativan) $0.5-1 \mathrm{mg}$ IV/po Q8H PRN agitation when patient is extubated

Acetaminophen (Tylenol) $650 \mathrm{mg}$ PR/po Q4H for temp greater than 38.5 degrees C* 
Acetaminophen/Oxycodone 325/5 (Percocet) 1-2 tabs po Q4H PRN pain when extubated and tolerating po*

*Adult: Do not exceed $4 \mathrm{gm}$ Acetaminophen (Tylenol) from all sources in a 24 hour period.

Milk of Magnesia $30 \mathrm{ml}$ po PRN constipation

All drips received from OR to be activated on admission

Amiodarone $900 \mathrm{mg} / 500 \mathrm{ml}$ D5W

Aprotinin until current bottle is empty

Dobutamine $500 \mathrm{mg} / 250 \mathrm{ml} \mathrm{D} 5 \mathrm{~W}$

Dopamine $400 \mathrm{mg} / 250 \mathrm{ml} \mathrm{D} 5 \mathrm{~W}$

Epinephrine $1 \mathrm{mg} / 250 \mathrm{ml} \mathrm{NS}$

119.

Insulin regular 250 units/250 ml NS per "ENDO" program with goal blood glucose range of 71-

Discontinue drip and initiate SubQ scale when: patient resumes po intake and diabetic medicines are

restarted, upon MD order, or when patient transfers out of CVRU.

Lidocaine $2 \mathrm{gm} / 250 \mathrm{ml} \mathrm{D} 5 \mathrm{~W}$ at $\mathrm{mg} / \mathrm{min}$

Milrinone (Primacor) $40 \mathrm{mg} / 200 \mathrm{ml} \mathrm{D} 5 \mathrm{~W}$

Nitroglycerin (NTG) $50 \mathrm{mg} / 250 \mathrm{ml} 5 \mathrm{~W}$

Nitroprusside (Nipride) $50 \mathrm{mg} / 250 \mathrm{ml} \mathrm{NS}$

Norepinephrine (Levophed) $16 \mathrm{mg} / 250 \mathrm{ml} \mathrm{NS}$

Page 4 of 4

1-5180-0003 CMC Post Cardio-pulmonary Bypass Adult Orders

1-5180-0003-a-8-06

Phenylephrine (Neosynephrine) $40 \mathrm{mg} / 250 \mathrm{ml}$ NS (note: concentration may be different than bag started in OR)

Propofol $1000 \mathrm{mg} / 100 \mathrm{ml}$ lipid base

Electrolyte replacement orders:

Calcium Chloride $1 \mathrm{gm}$ IV over 10-20 minutes PRN ionized Calcium 0.94 or less

Magnesium Sulfate $2 \mathrm{gm} \mathrm{IV} \mathrm{x} 1$ dose, then $1 \mathrm{gm} \mathrm{IV} \mathrm{Q8H} \mathrm{x} 3$ doses PRN serum magnesium less than 1.9

Maintain Potassium level 4 - 4.5:

Central Line: $\mathrm{KCl} 10 \mathrm{mEq} / 50 \mathrm{ml}$ sterile water over 30 minutes. May repeat up to 3 doses (30 mEq

total)

Recheck serum potassium, redose as needed

Peripheral Line: $\mathrm{KCl} 10 \mathrm{mEq} / 50 \mathrm{ml}$ sterile water over 60 minutes. May repeat up to 3 doses $(30 \mathrm{mEq}$ total)

Recheck serum potassium, redose as needed.

Oral: $\mathrm{KCl} 20 \mathrm{mEq}$ x 1 dose for serum potassium 3.6 - 4

Give $\mathrm{KCl} 40 \mathrm{mEq} \times 1$ dose for serum potassium less than or equal to 3.5

Recheck serum potassium 4 hours after dose, redose as needed.

PropofolWeaning (Fast Track)

1. Chest drainage less than $100 \mathrm{ml} /$ hour. Must be less than $50 \mathrm{ml} /$ hour to extubate

2. Hemodynamically stable with $\mathrm{CI}$ greater than 2

3. Temperature greater than $35^{\circ} \mathrm{C}$

4. $\mathrm{PaO}_{2}$ greater than 80 on no more than $45 \% \mathrm{FIO}_{2}$ and $5 \mathrm{~cm}$ peep

5. For Epinephrine or Norepinephrine (Levophed) drips, check with MD prior to weaning propofol. All other drips are acceptable

6. Propofol infusion begun at approximately $50 \mathrm{mcg} / \mathrm{kg} / \mathrm{minute}$ in OR. After ventilator weaning criteria met, decrease infusion by half to $25 \mathrm{mcg} / \mathrm{kg} / \mathrm{minute}$. After 15 minutes, discontinue Propofol infusion.

Post Extubation Orders / Prior to transfer orders;

TCDB Q2H x 48 hours

* Discontinue NG/OG tube upon extubation

Discontinue pressure lines per established guidelines or for transfer to $6 \mathrm{~T}$

Dietary

NPO until extubated

NPO with ice chips for 4-6 hours post extubation $2000 \mathrm{ml}$ Fluid restriction

HDPD diet

HDPD, ADA diet, Calories

Activity Level

Bedrest operative day until extubated

* Dangle 2 hours post extubation if patient hemodynamically stable, progress to OOB

DATE:

TIME:

MD SIGNATURE: 
Carolinas Medical Center

Tight Blood Glucose Control Orders for

Adult Patient in MICU, SICU, TICU, DHU, CVRU, or Neuro ICU

(Target $80-120 \mathrm{gm} / \mathrm{dL}$ )

EndoTool_Program

Do not use this order set to manage a patient with diabetic ketoacidosis (DKA)

unless approved by the Attending Physician.

Initiate: CMC Tight Glucose Control for Adult Patient in MICU, SICU, TICU, DHU, CVRU, or Neuro ICU

Nursing

1. Check blood glucose via finger stick or laboratory (BMP, CMP, or glucose) upon arrival to unit and PRN for symptoms

and/or changes in vital signs, neurological status, or nutrition status.

2. For known Diabetic Patient: a) If glucose greater than $130 \mathrm{gm} / \mathrm{dL}$ : initiate insulin infusion according to Insulin Infusion Orders below.

b) If glucose $130 \mathrm{gm} / \mathrm{dL}$ or less: check glucose Q6H. Initiate Insulin Infusion

Orders below if any blood glucose is greater than $130 \mathrm{gm} / \mathrm{dL}$.

For Non-Diabetic Patient: a) If glucose greater than $130 \mathrm{gm} / \mathrm{dL}$ : initiate insulin infusion according to Insulin Infusion Orders below.

b) If glucose $130 \mathrm{gm} / \mathrm{dL}$ or less: check glucose every AM. Initiate

Insulin Infusion Orders below if any blood glucose is greater than

$130 \mathrm{gm} / \mathrm{dL}$.

3. If an IV insulin infusion is started for tight glucose control: discontinue all current insulin orders, including PRN, sliding

scale, continuous infusion, and/or scheduled bolus doses.

4. Prior to starting the infusion, waste approximately $30 \mathrm{ml}$ of the insulin mixture through the IV tubing prior to starting in

order to saturate the plastic tubing with insulin.

INSULIN INFUSION ORDERS

1. The patient must be on steady nutritional support to be eligible for EndoTool ${ }^{\mathrm{TM}}$ insulin dose calculations. This nutrition can be steady IVs with dextrose solutions, steady tube feedings, or TPN. Alternative blood glucose control measures must be used if patient is eating or receiving intermittent tube feedings. Titration of the TPN or titration of the tube feeding or titration of clear liquids is allowed with the EndoTool ${ }^{\mathrm{TM}}$ protocol.

2. Start the EndoTool ${ }^{\mathrm{TM}}$ Program by entering the necessary patient information into the computer.

i. If patient is currently on the EndoTool ${ }^{\mathrm{TM}}$ Program and is transferring from another intensive care

unit: enter the "BR" and "f" factors if known.

ii. If patient is transferring from a non-intensive care unit: search for patient by medical record

number in the inactive file by clicking on the View inactive patients link under the System Tasks heading.

3. Follow EndoTool ${ }^{\mathrm{TM}}$ Program instructions for insulin infusion rates, bolus doses, D50W doses, and blood glucose

determination frequency. For glucose levels $80 \mathrm{mg} / \mathrm{dL}$ or less: the insulin infusion is zero (0.0) or OFF.

EndoTool ${ }^{\mathrm{TM}}$ will print MAR stickers and orders for all calculated doses. Nurse must obtain a physician order to give any dose that is not the calculated dose.

4. Use a micro-pump for insulin infusion and attach into a "Y" site as close to where the IV is inserted into the

patient as possible with compatible IV fluids that infuse at a constant rate of at least $30 \mathrm{ml} / \mathrm{hour}$.

5. Insert Daily Summary Report and Order Sheet generated by EndoTool ${ }^{\mathrm{TM}}$ Program each morning into patient's chart for documentation of the glucose readings and insulin doses administered.

6. If patient is on TPN or tube feeding that is interrupted for more than 30 minutes while on the insulin infusion: run

D 10 W IV at the same rate as the interrupted TPN or tube feeding rate (Must have OK from Neurosurgery if Neurosurgery is attending or consulting). Check glucose Q1H after a change in nutrition status and PRN STOPPING EndoTool TM PROGRAM

1. Discontinue EndoTool ${ }^{\mathrm{TM}}$ Program once the patient is allowed to eat and contact the primary physician regarding

further orders for blood glucose management.

a. Stop insulin drip once alternative diabetic treatment is ordered and started.

b. "IV Insulin Drip Orders" option may be printed with a physician order and used if patient is ordered to remain on an insulin drip and is being transferred to another critical care unit.

2. Print the last MAR/Orders from the "Print Patient Reports/Orders" option and place in the patient's chart.

3. If patient is transferring out of current room: click on the Patient Information tab and change the patient's status to

"inactive" by changing the "Active" status from "Y" to "N". Click "Save \& Continue" to save the information.

Pharmacy

1. Mix 250 units of Regular Insulin in $250 \mathrm{ml} \mathrm{NS}$.

2. Mix all IV medications in NS or $1 / 2$ NS when possible.

Date: Time:

MD Signature: 
TABLE E1. P-values for significant predictors $(p<0.1)$ of OIP before and after propensity score adjustment

\begin{tabular}{lcc}
\hline & $\begin{array}{c}\text { Before } \\
\text { Adjustment }\end{array}$ & $\begin{array}{c}\text { After } \\
\text { Adjustment }\end{array}$ \\
\hline Gender & 0.05 & 0.90 \\
Hypertension & 0.01 & 0.88 \\
COPD & 0.01 & 0.97 \\
Unstable angina & 0.01 & 0.98 \\
Recent myocardial infarction & 0.01 & 0.80 \\
Age $>$ 75 years & 0.08 & 0.89 \\
Ejection fraction $<40$ & 0.01 & 0.97 \\
NYHA class & 0.01 & 0.98 \\
Three-vessel disease & 0.01 & 0.99 \\
Case priority & 0.01 & 0.96 \\
Type of surgery & 0.01 & 0.99 \\
\hline
\end{tabular}

